\title{
High time resolution measurements of precipitable water vapor from propagation delay of GPS satellite signals
}

\author{
T. Yoshihara ${ }^{1}$, T. Tsuda ${ }^{1}$, and K. Hirahara ${ }^{2}$ \\ ${ }^{1}$ Radio Science Center for Space and Atmosphere, Kyoto University, Kyoto 611-0011, Japan \\ ${ }^{2}$ Graduate School of Science, Nagoya University, Nagoya 464-8602, Japan
}

(Received November 15, 1999; Revised June 2, 2000; Accepted June 2, 2000)

\begin{abstract}
We estimated precipitable water vapor (PWV) with a high time resolution using Global Positioning System (GPS) measurements taken at Shigaraki, Japan, in 1995, and Yamagawa, Japan, in 1996. We have compared PWV determined from GPS data with radiosonde, radiometer and ceilometer data. Comparison between the GPS and radiosonde data shows that the GPS results, with a high time resolution of as little as 6 min. correctly provided the absolute PWV with an error of about $8 \mathrm{~mm}$ related to site coordinate errors. In a comparison between the GPS and radiometer (in the zenith direction) data, the GPS 6-minute-derived PWV agree in their perturbations with radiometer results. We also compared these good time resolution GPS results obtained at three receivers located within a distance of several hundred meters of each other. As a result, these PWV were in agreement within an absolute accuracy of about $4 \mathrm{~mm}$. Finally, we compared the GPS results with the zenith delay caused by water vapor which was assumed to be contained in the lowest cloud layer, whose bottom height and thickness were determined with a ceilometer. We found good agreement of relative zenith delay perturbations between the GPS (estimated every $1 \mathrm{~min}$.) and ceilometer results, especially in the case of a cloud bottom height of as low as $100 \mathrm{~m}$ within RMS of $1.0 \mathrm{~mm}$. From these results, GPS has the potential to detect small changes of water vapor quantity.
\end{abstract}

\section{Introduction}

The Global Positioning System (GPS) is a satellite navigation system developed in the U.S., that enables one to accurately determine ones position, velocity and time anywhere on or near Earth. For scientific applications of GPS, "Static Positioning" is now widely utilized, especially for geophysical phenomena, by measuring the carrier phase of a GPS signal. It is expected that highly accurate static positioning measurements will be useful for detecting the motion of tectonic plates, and also to predict earthquakes and volcanic processes.

Precise orbital elements (so-called precise ephemerides) of GPS satellites are provided by the IGS (International GPS Service for Geodynamics). We can obtain these products through the INTERNET with a delay of about two weeks. The reduction of satellite orbit errors, which are currently several centimeters, has greatly contributed to the improvement of positioning measurements with GPS.

The effects of the propagation medium on GPS signals can be categorized by two kinds of atmosphere; the ionized and the neutral atmosphere. These effects are called "ionospheric delay" and "tropospheric delay," respectively. Ionospheric delay can be eliminated by measuring the delay with a dual-frequency receiver utilizing the dispersion relation of the refractive index for an ionized gas.

Tropospheric delay can be separated into "dry" and "wet" components (Hopfield et al., 1969). The former (so-called

Copy right (C) The Society of Geomagnetism and Earth, Planetary and Space Sciences (SGEPSS); The Seismological Society of Japan; The Volcanological Society of Japan; The Geodetic Society of Japan; The Japanese Society for Planetary Sciences. "hydrostatic delay") results from the dry atmosphere density and the latter (so-called "wet delay") from the water vapor content. The hydrostatic delay can be accurately determined by surface pressure measurements. If the surface pressure is given to $0.3 \mathrm{hPa}$ or better then the hydrostatic delay can be reduced to less than $1 \mathrm{~mm}$ (Businger et al., 1996). On the other hand, the wet delay in the zenith direction, which is called the "Zenith Wet Delay (ZWD)", varies from less than $10 \mathrm{~mm}$ in a dry area to as much as $400 \mathrm{~mm}$ in a humid region (Elgered et al., 1990). It is known that the wet delay is nearly proportional to the quantity of water vapor, integrated along the signal path.

The tropospheric delay (total of hydrostatic and wet delay) can be estimated from GPS data by a least square method simultaneously with other parameters (e.g. coordinates of receiver stations). Because the quantity of water vapor changes greatly, wet delay currently determines the limit of GPS accuracy.

The relation between ZWD and PWV is given as follows (Askne and Nordius, 1987),

$$
\mathrm{ZWD}=\Pi^{-1} \mathrm{PWV}
$$

where the dimensionless constant $\Pi$, related to the weighted mean temperature of the wet part of atmosphere $T_{m}$, is approximately 0.15 and varies with the summation of the local climate (e.g. location, elevation and season) by as much as 15\% (Bevis et al., 1992). The variable $T_{m}$ is represented as follows (Davis et al., 1985),

$$
T_{m}=\frac{\int \frac{P_{v}}{T} d z}{\int \frac{P_{v}}{T^{2}} d z},
$$




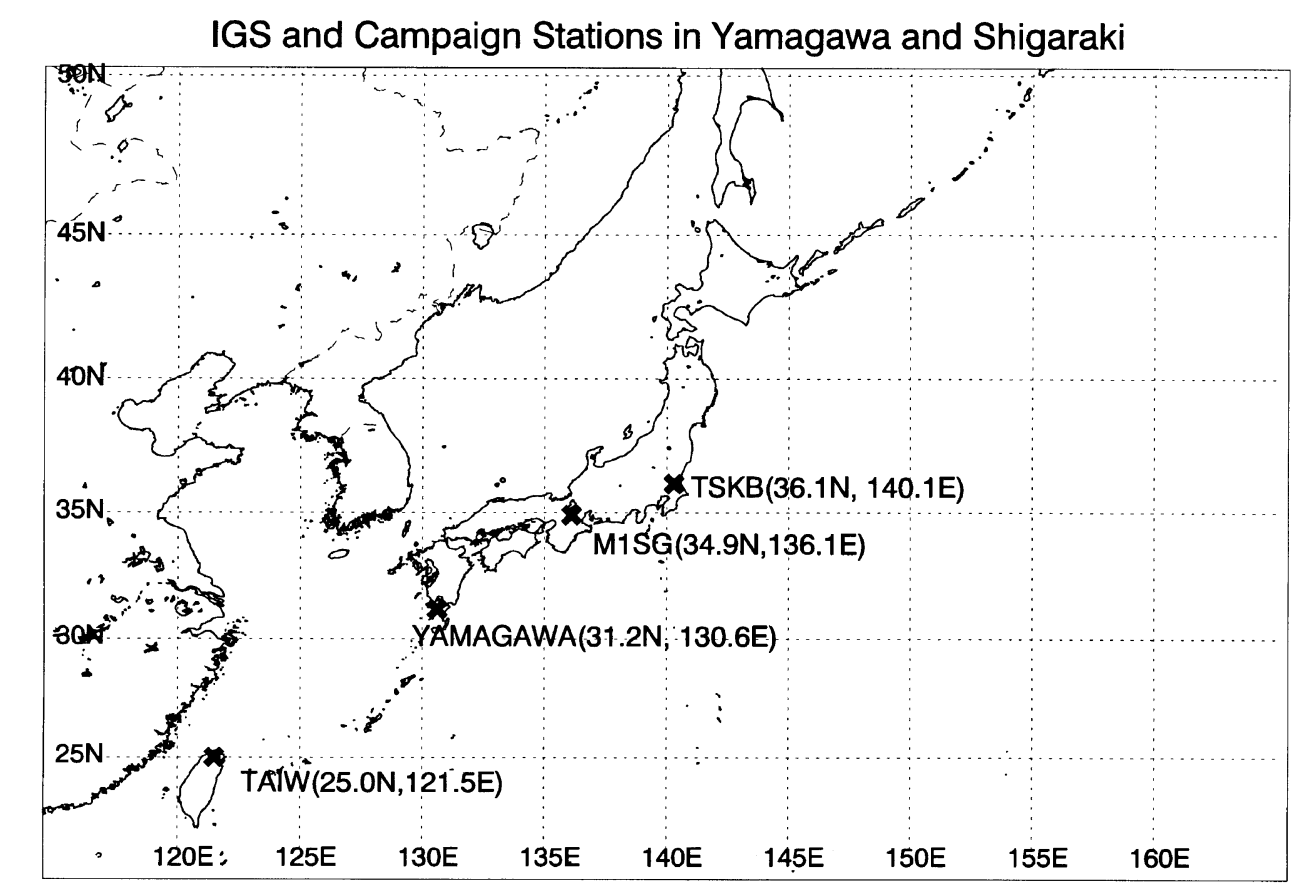

Fig. 1. Locations of IGS stations used as references for the campaign in Yamagawa and Shigaraki. The Location of the Yamagawa Radio Observatory and the Shigaraki MU Observatory are indicated as YAMAGAWA and M1SG, respectively.

Table 1. Coordinates of GPS receivers used during the Yamagawa campaign in 1996. The coordinates of Tsukuba (IGS station) were derived from SINEX file COD08557.SNX. While the coordinates of the GPS stations in Yamagawa were obtained by BERNESE analysis of the entire campaign period.

\begin{tabular}{|c|c|c|c|}
\hline GPS station & $\begin{array}{r}\mathrm{x}, \mathrm{y}, \mathrm{z} \text { components } \\
\text { of coordinates }\end{array}$ & $\begin{array}{l}\text { Latitude } \\
\text { Longitude } \\
\text { Height }\end{array}$ & $\begin{array}{r}\text { Distance } \\
\text { from CENT }\end{array}$ \\
\hline CENT & $\begin{array}{r}-3554610.4446 \mathrm{~m} \\
4144908.5110 \mathrm{~m} \\
3285389.8065 \mathrm{~m}\end{array}$ & $\begin{array}{c}31^{\circ} 12^{\prime} 17^{\prime} \mathrm{N} \\
130^{\circ} 36^{\prime} 57^{\prime} \mathrm{E} \\
111.3150 \mathrm{~m}\end{array}$ & - \\
\hline JUNI & $\begin{array}{r}-3554842.6544 \mathrm{~m} \\
4144801.4376 \mathrm{~m} \\
3285287.2878 \mathrm{~m}\end{array}$ & $\begin{array}{l}31^{\circ} 12^{\prime} 13^{\prime \prime} \mathrm{N} \\
130^{\circ} 37^{\prime} 66^{\prime \prime} \mathrm{E} \\
117.9817 \mathrm{~m}\end{array}$ & $275.5 \mathrm{~m}$ \\
\hline PRIM & $\begin{array}{r}-3554127.4462 \mathrm{~m} \\
4145200.8903 \mathrm{~m} \\
3285560.2358 \mathrm{~m}\end{array}$ & $\begin{array}{c}31^{\circ} 12^{\prime} 23^{\prime \prime} \mathrm{N} \\
130^{\circ} 36^{\prime} 36^{\prime} \mathrm{E} \\
120.5394 \mathrm{~m}\end{array}$ & $589.7 \mathrm{~m}$ \\
\hline $\begin{array}{c}\text { TSKB (IGS) } \\
\text { (Tsukuba) }\end{array}$ & $\begin{array}{r}-3957199.2379 \mathrm{~m} \\
3310199.7124 \mathrm{~m} \\
3737711.6570 \mathrm{~m}\end{array}$ & $\begin{array}{l}36^{\circ} 6^{\prime} 20^{\prime \prime} \mathrm{N} \\
140^{\circ} 5^{\prime} 15^{\prime \prime} \mathrm{E}\end{array}$ & $1031.2 \mathrm{~km}$ \\
\hline
\end{tabular}

where $P_{v}$ and $T$ are the water vapor pressure and absolute temperature, respectively. In this study, we estimate $\Pi$ with a mean value of $T_{m}$ obtained from radiosonde profile of temperature and humidity by using Eq. (2).

Although the inaccuracy of wet delay produces an error in position measurements, it can be used to estimate the integrated water vapor content in the atmosphere, which is commonly called precipitable water vapor (PWV). In other words, we can apply GPS measurements to meteorology.

There are not many methods for PWV measurements with good time and spatial resolution. However, the application of GPS as a PWV monitor has recently been highlighted as a powerful instrument for this measurement because of portability and simplicity of operation. This has the potential to provide a powerful constraint for numerical weather prediction (NWP) models (Kuo et al., 1993) and in weather analysis. As an added benefit, it is expected that meteorological results will provide information for the improvement of GPS positioning.

A GPS receiver network has been established by the Geographical Survey Institute (GSI) at about one thousand points over Japan. This corresponds to an average spacing of $25 \mathrm{~km}$. Although the GPS data are routinely processed to detect seismic deformations, the 3 hours resolution of PWV are provided as meteorological signals. GPS receivers usually record signals from a GPS satellite with a lower cut off elevation angle of $15^{\circ}$. BERNESE, that we used for analysis of GPS data, does not directly estimate PWV overhead, but, it averages PWV in a conic volume extending over a wide area, by projecting the slant delay at various directions into the zenith direction. We have assumed that the scale height of water vapor is about $3 \mathrm{~km}$. Then, the PWV estimated from GPS data represents the mean value for the atmosphere with a horizontal scale of about $20 \mathrm{~km}$. Therefore, it is suspected that the GPS receivers of GSI, which are about $25 \mathrm{~km}$ apart, measure independent PWVs.

The relative change in the water vapor distribution all over Japan was estimated with the GSI-GPS network, and the passage of a cold front was documented (Iwabuchi et al., 1997). Therefore, the nation wide GSI-GPS network has successfully detected the PWV distribution associated with synoptic scale meteorological phenomena with time and spatial reso- 
lutions of 3 hours and $25 \mathrm{~km}$, respectively.

In this paper, we report our investigation of high-time resolution measurement of PWV using the GPS zenith delay. To accomplish this, we participated in two GPS campaigns, one in Yamagawa in June 1996 and the other in Shigaraki in November 1995. In particular, we investigated the correlation of PWV, determined with the GPS method, and conventional meteorological instruments, such as a radiosonde, a microwave radiometer and a ceilometer. Then, we processed PWV data with a time resolution of a few minutes, applying a novel technique, and used the data to study mesoscale meteorological disturbances, such as a cold front, a thunderstorm and a torrential rainfall.

We summarize the basic features of the two campaign observations in Yamagawa and Shigaraki in Section 2. These campaigns were designed to study detailed variations of PWV with an array of GPS receivers. In Section 3, we discuss the investigation of a suitable set of analysis parameters of BERNESE software for this study. We especially examined the time resolution of the analysis. In Section 4, we discuss the GPS-PWV results analyzed with these parameters and compare them to the GPS-derived PWV with simultaneous results obtained with meteorological instruments, and discuss their correlation with a time resolution of several minutes.

\section{GPS Campaigns on Detailed PWV Variations}

2.1 Coordinated measurements with various meteorological instruments in Yamagawa during a Baiu front activity in 1996

Coordinated observations, named TREX (Torrential Rain EXperiment), were carried out in the south Kyushu area of Japan, during June and August, 1996, in order to study meteorological disturbances associated with a Baiu front. Seven research groups from universities and national research institutes participated in the campaign, operating a variety of insitu and remote-sensing equipment, such as a balloon-borne radiosonde, a meteorological Doppler radar, dropsonde released from an aircraft, a Boundary Layer Radar (BLR), etc. The Radio Atmospheric Science Center (RASC) of Kyoto University joined the experiment at the Yamagawa Radio Observatory $\left(31.2^{\circ} \mathrm{N}, 130.6^{\circ} \mathrm{E}\right)$ of the Communications Research Laboratory (CRL), Ministry of Posts and Telecommunications, in collaboration with CRL and Kagoshima University. We continuously operated a BLR and a ceilometer at the observatory, and launched a radiosonde at intervals between 3 and 24 hours during a disturbed-weather event.

We also installed three GPS receivers on June 13-25 within and outside the observatory in order to study PWV with good time resolution, which is the main subject of this paper. We discuss in Section 4 the correlation between PWV estimated from the wet delay of GPS signals and atmospheric parameters obtained with meteorological instruments.

Three GPS receivers (receiver type: Ashtech Z-XII3) were located at the Yamagawa Radio Observatory, Taisei Primary School (western site), and Yamagawa Junior High School (eastern site), which were named CENT, PRIM and JUNI, respectively. The GPS receiver was installed on the roof of each building. The distances between the three sites, which are nearly aligned in the west-east direction, are summarized in Table 1.

A specific GPS signal sampling interval of $10 \mathrm{sec}$. was selected. However, the observed data were sorted with a time resolution of $30 \mathrm{sec}$., when combined with the IGS data for the double difference measurements so as to adjust to the sampling interval of the IGS data, whose coordinates were provided weekly in a SINEX (Solution Independent EXchange) format through the INTERNET. As a reference IGS station, we mainly used TSKB (Tsukuba-city, about $1031 \mathrm{~km}$ east of CENT). The Coordinates of these GPS receiver stations are shown in Table 1, while the map locations are indicated in Fig. 1.

We employed a balloon-borne radiosonde (VAISALA RS$80-15 \mathrm{~N})$, consisting of a barometer, thermometer and a hydrometer. The measured data were transmitted to a receiver every 2 seconds on a frequency-modulated radiowave. The profiles of pressure, temperature and humidity could be obtained with a height resolution of $100 \mathrm{~m}$. The horizontal location of a radiosonde was determined using a VLF radio navigation system. Then, the horizontal motion of the rawinsonde, i.e., horizontal winds, was derived from the time derivative of the horizontal position.

During a meteorologically disturbed condition, we launched radiosondes from the Yamagawa observatory at irregular intervals. In particular, a total of 19 rawinsondes were launched on June 15-25 when the GPS receivers were operated. We estimated PWV from the rawinsonde data by using the trapezoid formula except for two rawinsonde data, which evidently provided erroneous profiles. It is noteworthy that rawinsondes were flown leeward by about $3-12 \mathrm{~km}$ at an altitude of $3 \mathrm{~km}$. Therefore, the radiosonde results may not necessarily represent the profile right above the observation point. They could be affected by horizontal variations of the weather field.

We further calculated the proportion constant, $\Pi$, in Eq. (1) from these 17 rawinsonde profiles and found that it varied from 0.1616 to 0.1657 with a mean of 0.1635 and a standard deviation of 0.0013 . Generally it is important to strictly examine PWV by using time-dependent $\Pi$. However, it was difficult to determine $\Pi$ with a time resolution as good as a few minutes. Although $\Pi$ can be inferred from the surface temperature (Bevis et al., 1992), we have assumed a constant for $\Pi$ and applied a value of 0.1635 to the entire data set. Therefore, the estimated PWV could include errors due to time variations of $\Pi$.

We installed a laser-ceilometer (VAISALA CT 12K) to determine the distribution of clouds, which is very useful for a study of PWV variations. A ceilometer transmits a laser pulse, and receives scattering from cloud particles using a telescope. It can detect the existence of clouds together with the distance to the scatterers with a height resolution of $15 \mathrm{~m}$. During the GPS campaign, we pointed the ceilometer in the zenith direction, so as to measure the height distribution of clouds. This ceilometer is capable of detecting the bottom height and thickness of the lowest two cloud layers below $3800 \mathrm{~m}$. Although the data were sampled at intervals of 12 sec., we averaged the results for $1 \mathrm{~min}$.

For the surface meteorological data, i.e. surface pressure, temperature, precipitation, etc., we referred to the hourly data obtained at the Kagoshima meteorological observatory, 


\section{Campaign in Yamagawa}

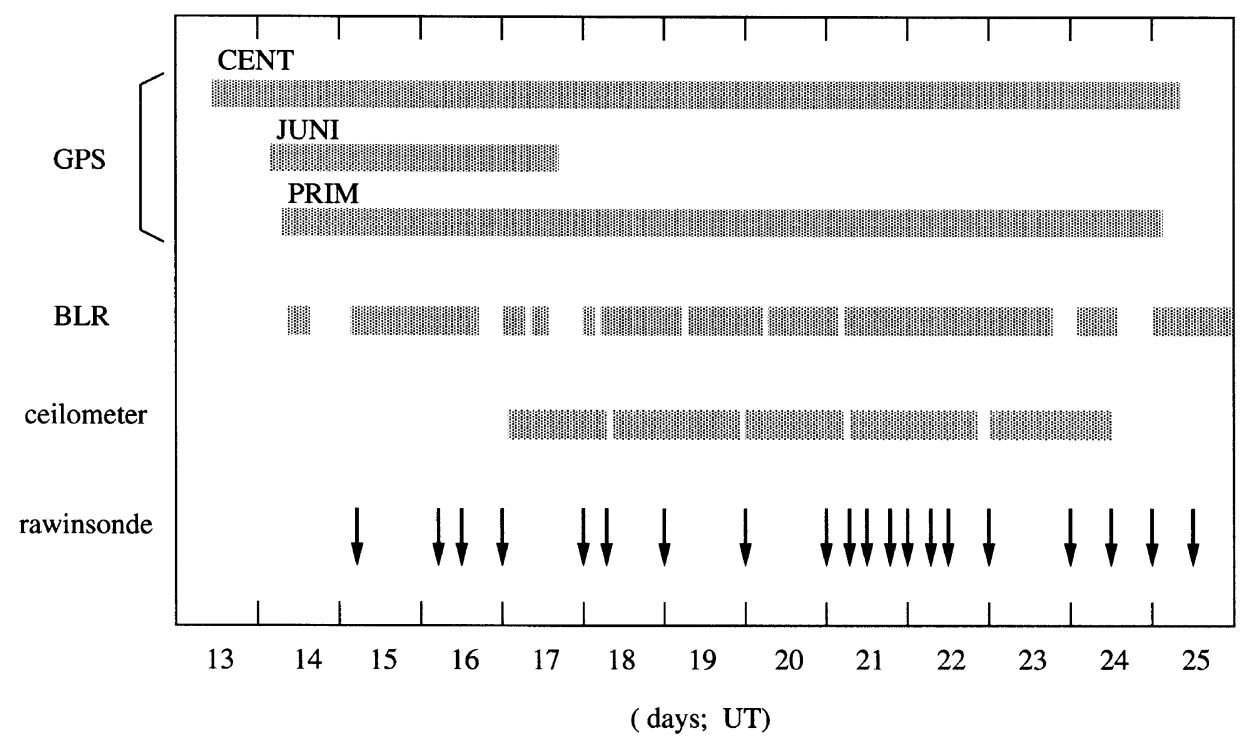

Fig. 2. Observation period for each measurement during the Yamagawa campaign on June 13-25, 1996.

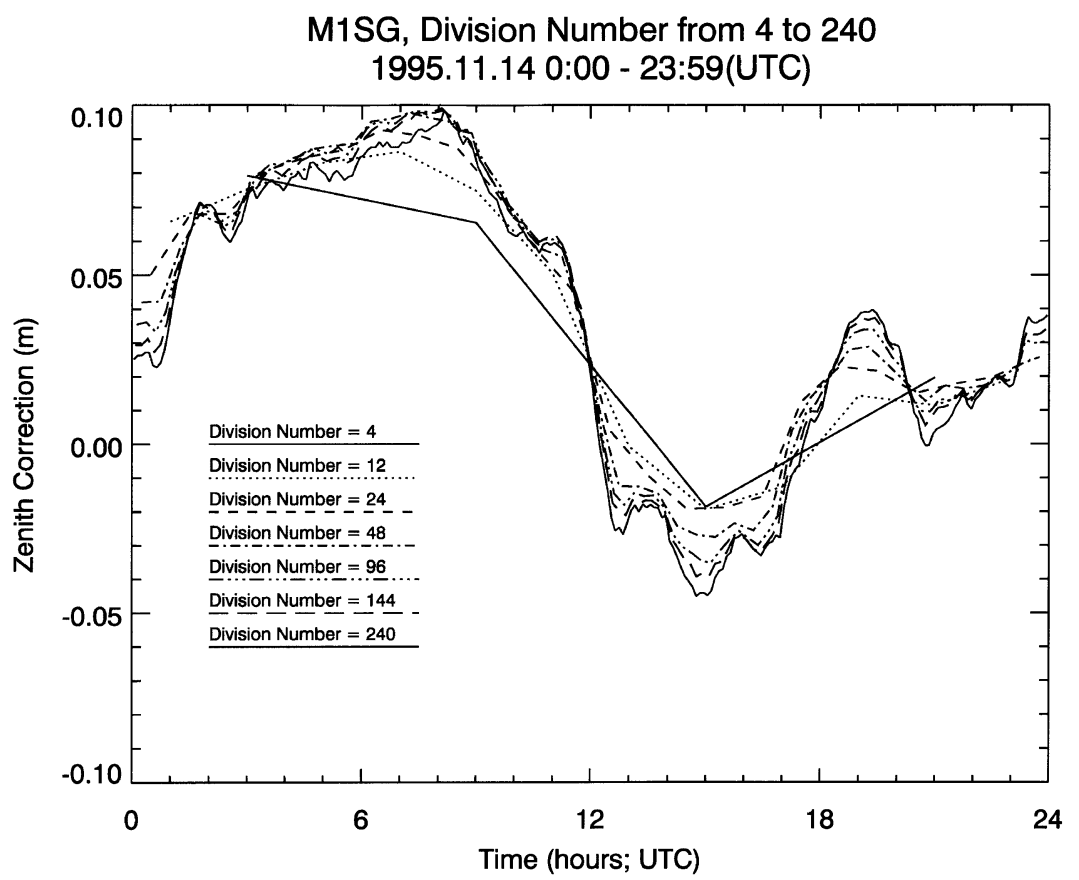

Fig. 3. Zenith delay correction for M1SG on November 14, 1995, with division numbers from 4 to 240. TSKB was chosen as the reference point.

which is located about $40 \mathrm{~km}$ north-northwest of the Yamagawa observatory, because we obtained no surface meteorological data at the Yamagawa observatory. We used surface pressure and temperature with a correction for height difference. The greatest pressure difference between the two sites, as estimated from a weather chart, during the campaign period was about $1.3 \mathrm{hPa}$, which may cause PWV error of about $0.4 \mathrm{~mm}$ with a synoptic time scale.

The detailed time periods for data gathering for the above measurements are shown in Fig. 2. During this campaign period, the weather conditions changed dramatically with the motion of a cold front, that passed from the north-west to the south-east, and a Baiu front, that passed from the north to the south over Yamagawa. Thunderstorms were often observed (e.g. around the passage of the cold front on June 17), and thus the surface temperature changed by about $20-30^{\circ} \mathrm{C}$ during these disturbances.

During the entire campaign period of about 11 days, we obtained GPS data from CENT and PRIM. However, we obtained data at JUNI for only about 3 days during 2 UT on June 14 and 21 UT on June 17 due to an accident. The ceilometer measurement data were available after June 17. A radiosonde was launched at $0 \mathrm{UT}$. Additional radiosonde experiments were mainly conducted on June 21-22. 
Table 2. Coordinates of GPS stations during the Shigaraki campaign in 1995. The coordinates of IGS stations derived from SINEX file COD08277.SNX. Note that the coordinates of M1SG were derived on analysis for November 14, 1995.

\begin{tabular}{crcc}
\hline $\begin{array}{r}\text { Reference } \\
\text { GPS stations }\end{array}$ & $\begin{array}{r}\text { x, y, z components } \\
\text { of coordinates }\end{array}$ & $\begin{array}{c}\text { Latitude } \\
\text { Longitude }\end{array}$ & $\begin{array}{r}\text { Distance } \\
\text { from M1SG }\end{array}$ \\
\hline & $-3776003.7436 \mathrm{~m}$ & $34^{\circ} 51^{\prime} 15^{\prime \prime} \mathrm{N}$ & \\
M1SG & $3633152.6392 \mathrm{~m}$ & $136^{\circ} 6^{\prime} 16^{\prime \prime} \mathrm{E}$ & - \\
(Shigaraki) & $3624859.1925 \mathrm{~m}$ & & \\
& $-3957199.2469 \mathrm{~m}$ & $36^{\circ} 6^{\prime} 20^{\prime \prime} \mathrm{N}$ & \\
TSKB (IGS) & $3310199.7092 \mathrm{~m}$ & $140^{\circ} 5^{\prime} 15^{\prime \prime} \mathrm{E}$ & $387.1 \mathrm{~km}$ \\
(Tsukuba) & $3737711.6670 \mathrm{~m}$ & & \\
& $-3024781.9503 \mathrm{~m}$ & $25^{\circ} 1^{\prime} 17^{\prime \prime} \mathrm{N}$ & \\
TAIW (IGS) & $4928936.8635 \mathrm{~m}$ & $121^{\circ} 32^{\prime} 12^{\prime \prime} \mathrm{E}$ & $1770.3 \mathrm{~km}$ \\
(Taipei) & $2681234.4182 \mathrm{~m}$ & & \\
\hline
\end{tabular}

Table 3. Major parameters related to ZD are shown with the suitable values that we propose for the high time resolution analysis with BERNESE Software Version 4.0.

\begin{tabular}{ll}
\hline Major parameter & Optimum value \\
\hline Station Coordinates & $\begin{array}{l}\text { fixed or } \\
\text { constrained strongly }\end{array}$ \\
Baseline length & several hundred km \\
$\begin{array}{l}\text { Minimum elevation angle } \\
\text { of GPS satellites }\end{array}$ & $15^{\circ}$ to $20^{\circ}$ \\
The number of baselines & one \\
The number of satellites & non-selective \\
\hline Relative constraints of ZD & 0.002 m \\
\hline
\end{tabular}

\subsection{Measurement of meso-scale disturbances with the GPS array around the Shigaraki MU observatory}

Another GPS campaign was conducted on November 1317, 1995, with 24 GPS receivers around the Shigaraki MU observatory $\left(34.9^{\circ} \mathrm{N}, 136.1^{\circ} \mathrm{E}\right)$ of RASC. This campaign was coordinated by an inter-university consortium, chaired by Prof. T. Tanaka of the Disaster Prevention Research Institute (DPRI) of Kyoto University, and aimed at obtaining a fundamental data-set for tomography of the water vapor distribution in the troposphere.

Following the traditional nomenclature, a station name of four characters is assigned to each GPS receiver, where the last two characters are SG. Within the Shigaraki MU observatory, six GPS receivers (type: Ashtech Z-XII3) among these 24 GPS receivers were installed within a short distance of each other, i.e. within a few hundred meters. In particular, M1SG, which was the station name, was set up on the roof of the observatory building and operated during the entire campaign period. The other 18 receivers were located in an area with a horizontal extent of about $6 \mathrm{~km}$ surrounding the MU observatory. This GPS receiver array seems to be useful for a study of horizontal variations of PWV. The programmed session lengths were different at each station due to the availability of a commercial power line and the data memory capacity. As for reference IGS stations, we mainly used TSKB and TAIW. The locations and coordinates of these GPS sites are summarized in Fig. 1 and Table 2.

A dual-frequency microwave radiometer (WVR; Radiometrics WVR-1000), which is a passive remote sensing instrument for water vapor, was installed on the roof of the observatory building, near the M1SG station. A WVR detects microwave radiation from the sky at $23.8 \mathrm{GHz}$ and $31.4 \mathrm{GHz}$, and determines the total quantity of water along a path in the view direction, separating the water amounts corresponding to water vapor and liquid water. However, the window of the microwave receiver sometimes becomes wet because of raindrops, morning dew, etc., and then the WVR estimate includes a significant error. During the campaign, the WVR was programmed to point in 13 directions with elevation angles of $5-175^{\circ}$ in the north-south direction. Therefore, PWV in the zenith direction was measured about every $33 \mathrm{~min}$., because it took about $2.5 \mathrm{~min}$. for the measurement in each direction.

A total of 6 radiosondes were launched from the Shigaraki MU Observatory during the GPS observation period. The radiosonde derived proportion constant, $\Pi$, varied from 0.1530 to 0.1544 with a mean of 0.1537 and a standard deviation of 0.0005 . As in the Yamagawa campaign, we used this mean value for the entire period of the Shigaraki campaign. The surface meteorological data, such as pressure, temperature, humidity, surface wind, precipitation, etc., were measured every $5 \mathrm{sec}$. at the Shigaraki MU Observatory.

A cold front passed above Shigaraki on November 14. Therefore the weather conditions changed greatly before and after this event. Section 4 contains the main discussion of the high time resolution results obtained at the M1SG station on November 14 and 15, and their comparison with the radiosonde and radiometer results.

\section{Variations of PWV Analyzed with High Time Resolution}

In this study, we employed BERNESE GPS Software version 4.0. We were chiefly interested in short term variations of GPS measurements. In the following subsections, we discuss some of the key parameters that are particularly important for accurate estimation of Zenith Delay (ZD) with a good time resolution, which means the tropospheric total delay in the zenith direction.

\subsection{A suitable set of parameters for GPS analysis soft- ware (BERNESE)}

We selected major parameters in BERNESE that are particularly related to the estimation of PWV, as shown in Table 3 .

It is proper to assume that the motion of a tectonic plate does not significantly affect an observation station during a week or so, except in the case of an earthquake. So it is reasonable to assume that the coordinates of the observation stations are fixed or strongly constrained. Then, rapid fluctuations of the estimated coordinates could be attributed to ZWD caused by humidity variations. The coordinates to be used, however, must be estimated in advance as a compara- 
Table 4. Characteristics of meteorological measurements in the Yamagawa and Shigaraki campaigns, and a viewpoint in this study.

\begin{tabular}{|c|c|c|c|}
\hline & Radiosonde & Microwave radiometer & Ceilometer \\
\hline Observation parameter & $\begin{array}{l}\text { vertical profiles of humidity, temperature, } \\
\text { wind velocity and pressure }\end{array}$ & PWV & $\begin{array}{l}\text { bottom height and thickness } \\
\text { of cloud }\end{array}$ \\
\hline Observation process & in-situ & remote sensing & remote sensing \\
\hline Accuracy & $\begin{array}{l}\text { good } \\
\text { (absolute PWV) }\end{array}$ & $\begin{array}{l}\text { good } \\
\text { (relative PWV) }\end{array}$ & $\begin{array}{l}\text { reasonable } \\
\text { (PWV in the lowest cloud can be } \\
\text { inferred using theoretical model) }\end{array}$ \\
\hline Time resolution & 3 to 12 hours & $\begin{array}{l}2.5 \mathrm{~min} . \\
33 \mathrm{~min} . \text { (zenith: in the present) }\end{array}$ & $12 \mathrm{sec}$. \\
\hline
\end{tabular}

YAMAGAWA(CENT, Reference point: TSKB) 1996.6.14-24 ( UTC )

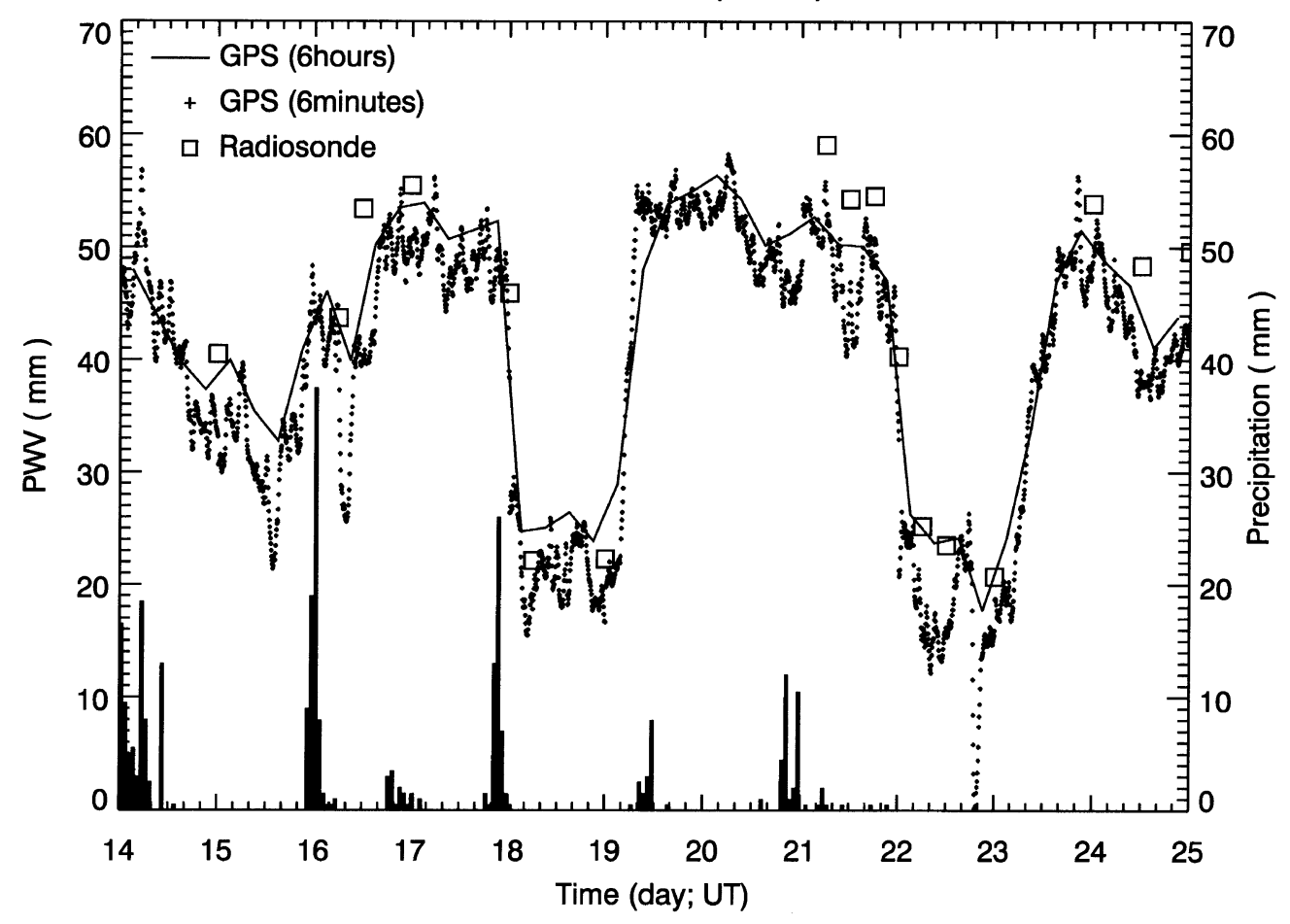

Fig. 4. Comparison of PWV between the radiosonde ( $\square$ ) and GPS results at CENT every 6 hours (solid line) and 6 min. (dot) with reference point TSKB during June 14 and 24, 1996. Hourly surface precipitation at Kagoshima is plotted in units of mm (column).

tive long time average (every four to six hours, i.e. the same way as for the typical geodetic analysis).

There is an important condition on the selection of reference points. It is difficult to separate ZD at the two ends of a short baseline when a similar mapping function is inferred. So, the reference point should be far enough from the observation site so that GPS satellite elevation angles are not identical. Generally, in the case of a baseline length of more than $1000 \mathrm{~km}$, the correlation of absolute PWV at the two ends of the baseline is small enough (Rocken et al., 1993). In this study, we selected a reference point more than several hundred kilometers away from an observation site.

The number of reference points surrounding the observation station should be as high as possible. But, then the num- ber of parameters to be estimated increases greatly. Here, we set the number of reference points as one. However, note that the number of common satellites at the two ends of a baseline decreases when the baseline is long. The cut-off elevation angle of the GPS satellites for analysis was set as $15-20^{\circ}$, following usual geodetic procedure.

The estimated ZD is time-dependent, representing the mean value within a time interval $\left(t_{i}, t_{i+1}\right)$. The constraints on the difference between two subsequent tropospheric delays (i.e. $\mathrm{ZD}\left(t_{i}\right)$ and $\mathrm{ZD}\left(t_{i+1}\right)$ ) are called "relative constraints". For ZD estimation with high time resolution, there is the problem that the estimated ZD has correlations at the two ends of the baseline when too large a value (e.g. $5 \mathrm{~m}$ ) for the relative constraint is selected. Thus, we selected the relative 
constraints of $0.002 \mathrm{~m}$ in this study.

The number of satellites is one of the parameters which is related to ZD. But in BERNESE, we cannot select satellites.

\subsection{Time Resolution of $\mathrm{ZD}$ Analysis}

In the BERNESE software, we first need to determine the length of a time series for analyzing the coordinates of observation points together with the ZD at the two ends of the baseline. That is, we should select the time resolution of the $\mathrm{ZD}$ estimation.

One session of original data records, which was 24 hours long in our case, can be divided into sub-time series of equal duration. Then, ZD can be estimated for an equal time interval, and the coordinates of the two ends of the baseline are given simultaneously, together with other parameters by a least mean square technique. For example, if we wish to produce results every 6 hours, we need to divide a 24 hour session by 4 , where this number is called the "division number of a session".

Figure 3 shows the time variations of ZD at M1SG during 0 and 24 UT on November 14, 1995, estimated by changing the division number from 4 to 240 , which corresponds to time resolutions of 6 hours and 6 min., respectively. Note that the displayed ZD values are corrected values for ZD which were calculated from the standard atmosphere model in the BERNESE software.

Detailed time variations of ZD are recognized in Fig. 3 with a better time resolution. It is noteworthy that the mean value of ZD averaged over 24 hours was nearly the same at about $0.037 \mathrm{~m}$ with a standard deviation of $0.0017 \mathrm{~m}$ regardless of the division number. Thus, the ZD values estimated with high time resolution are not contradictory to the results that would be obtained using the usual geodetic analysis (i.e. estimated with a time resolution of 6 hours). Figure 3 also indicates that short time-scale fluctuations show a similar structure, with changing time resolution.

Although the BERNESE software is not recommended for analysis with a time resolution of less than 2 hours, we found that the results estimated every $6 \mathrm{~min}$. were not inconsistent with those obtained by a normal geodetic procedure with a coarser time resolution. So, there is the potential that ZD could reflect changes in the water vapor content with high time resolution.

\section{Comparison of PWV with Meteorological Mea- surements}

We compared PWV data obtained with GPS to simultaneously obtained meteorological observations by means of in-situ and remote-sensing techniques. In particular, we employed balloon-borne radiosondes, a microwave radiometer and a ceilometer, whose measurement characteristics are summarized in Table 4.

\subsection{Radiosonde}

We first discuss a comparative study with radiosonde measurements during the Yamagawa campaign in 1996. Figure 4 shows time variations of the GPS-derived PWV at CENT during June 14 and 24, with time resolutions of 6 hours and 6 min. We used TSKB as a reference IGS site.

PWV with a time resolution of 6 hours was first estimated every day. Then, these daily results were combined and analyzed again for the entire observation period of 11 days. But the PWV with a time resolution of $6 \mathrm{~min}$. was not processed with the combination of daily results because of the restriction of the dimension number in the BERNESE software. So, there are gaps at both ends of a day.

We carried out irregularly spaced radiosonde soundings 17 times with intervals of from 3 to 24 hours. PWV obtained by integrating a humidity profile from radiosonde measurement is plotted in Fig. 4. The hourly precipitation at the Kagoshima weather station is also presented in this figure.

There is good agreement in the overall structure of the PWV variations between the GPS 6 min. resolutions and radiosonde results, confirming again the validity of the PWV estimation by high time resolution GPS analysis. The mean difference of the GPS derived PWV relative to radiosonde results during the entire observation period was $8.25 \mathrm{~mm}$ and $3.14 \mathrm{~mm}$ for $6 \mathrm{~min}$. and 6 hours determination, respectively. Note that for the comparison with radiosonde results, we used the closest point and a linearly interpolated value for the GPS $6 \mathrm{~min}$. and 6 hours determinations, respectively. The bias in favor of the GPS 6 hour results seems to represent a coordinate error due to the short observation period of 11 days. We suspect that for the GPS 6 min. analysis, an additional bias of about $5 \mathrm{~mm}$ is produced due to a correlation between the delay and vertical coordinate determination, even though we have strongly constrained the coordinates. As a matter of fact, we observed that the estimated length of the baseline varies in proportion to the division number of $\mathrm{ZD}$.

After subtracting the bias, we have calculated RMS of the difference of PWV between the radiosonde and GPS results. It was about 3.10 and $3.66 \mathrm{~mm}$ for the $6 \mathrm{~min}$. and 6 hours analysis, respectively. The RMS difference was slightly smaller for the $6 \mathrm{~min}$. analysis. Note that we excluded data at $0 \mathrm{UT}$ from the RMS calculations because part of the data is missing at the end of a day for a daily solution with 6 min. GPS analysis.

During the 11 days of the observation period a cold front and a Baiu front were very active and passed over the Yamagawa observatory several times, therefore, the daily mean PWV content varied from 20 to $60 \mathrm{~mm}$ with sharp changes within a few hours. However, both sets of GPS results followed these rapid variations very well. This comparison suggests that the GPS estimation of PWV with 6 min. resolution correctly provides the absolute value of PWV. Moreover, short period fluctuations of PWV seem to reflect humidity variations caused by meteorological disturbances.

\subsection{Microwave radiometer}

Figure 5 shows a comparison of PWV between a microwave radiometer, a radiosonde and GPS on November 14 during the Shigaraki campaign. PWV in the zenith direction from the radiometer measurement is plotted with a time resolution of about 33 min. PWV was estimated with GPS every 6 min. with TAIW as the reference site.

The GPS results coincide fairly well with PWV obtained with the radiometer except for during 5 and $11 \mathrm{UT}$, and around 19-21 UT. In the former period, we suspect that the radiometer results were contaminated by precipitation, which was actually detected with a rain gauge at the MU radar observatory. Note that a bit precipitation of less than $0.5 \mathrm{~mm}$ was also observed at $19 \mathrm{UT}$ although precipitation was not plotted in Fig. 5. 


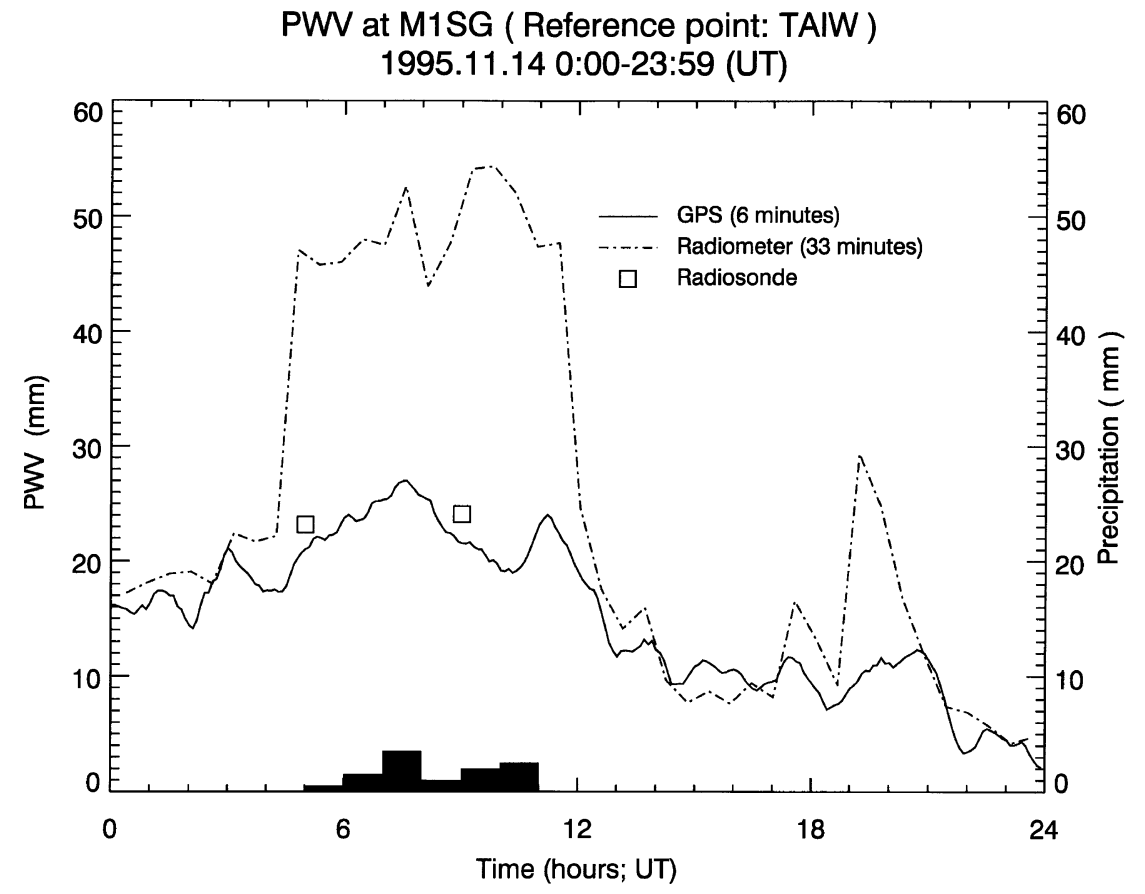

Fig. 5. Comparison of PWV between the radiometer (chained line) and GPS results (solid line), which were estimated every 6 min. on November 14, 1995, at M1SG, with TAIW as the reference point. PWV estimated with a radiosonde is shown as $\square$. Solid bar indicates precipitation in units of mm for more than $0.5 \mathrm{~mm}$.

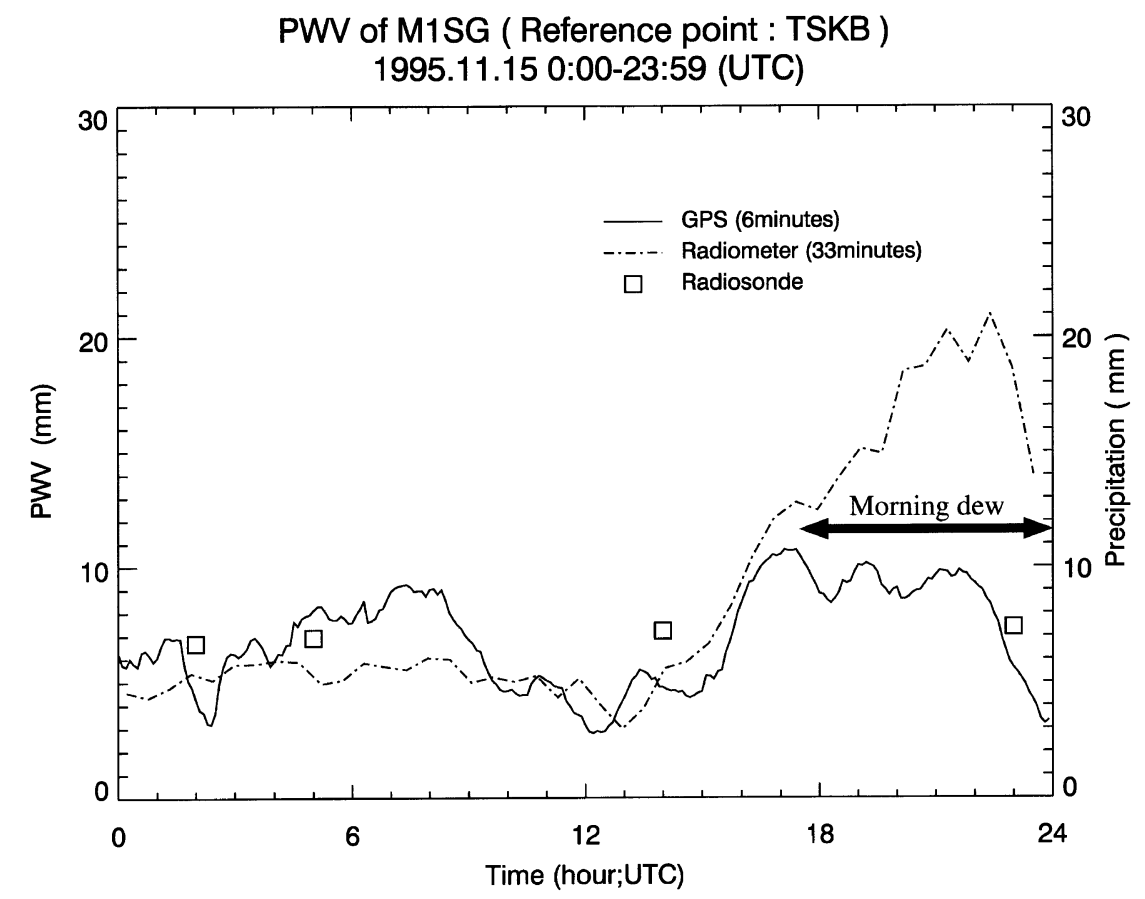

Fig. 6. The same as for Fig. 5, except the date was November 15, 1995. As a reference point, TSKB was selected.

For the period of the discrepancy found between the radiometer and GPS, we referred to an additional radiosonde result, as shown in Fig. 5, which agreed very well with the GPS-derived PWV. In the same manner as in the comparison with radiosonde, we calculated a bias and RMS value between radiometer and $6 \mathrm{~min}$. GPS estimation as $1.43 \mathrm{~mm}$ and $2.44 \mathrm{~mm}$, respectively. This RMS was smaller than the comparison with radiosonde. Since the data to compare with
6 min. GPS result was provided with a better time resolution than radiosonde, the GPS-PWV perturbation seemed to be more fairly evaluated. Note that we processed these analysis except for the data of the rainy periods (i.e. 5-11 UT and 19-21 UT on November 14). Quantitative changes in water vapor due to the passage of a cold front were reflected by both the GPS and radiometer results. On comparing the two sets of results, the characteristics of the changes were found 
YAMAGAWA (PRIM, CENT, JUNI; reference point: TSKB) 1996 JUN 16 00:00 - 23:59 (UT)

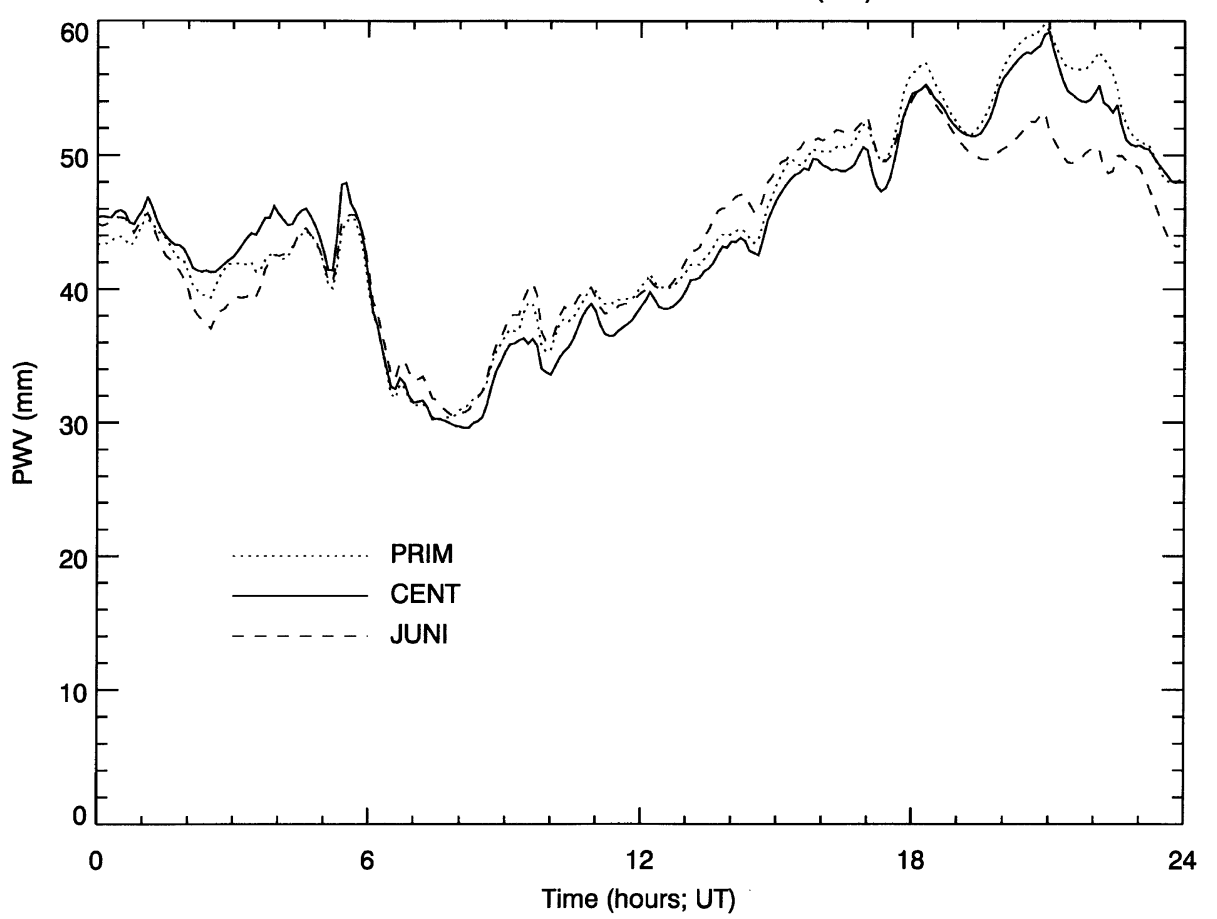

Fig. 7. Comparison of PWV among the three stations at Yamagawa, i.e. PRIM, CENT and JUNI, on June 16, 1996. These PWV were estimated with a estimation interval of $6 \mathrm{~min}$. The reference point was TSKB. Note that these PWV were estimated through the processing for each baseline.

to be generally similar.

Figure 6 presents another comparison of PWV between GPS and the radiometer on November 15,1995 . TSKB was selected as the reference point instead of TAIW, because an unusualy large standard deviation was detected in the results when TAIW was used. Note that the absolute value of PWV was less than half that in Fig. 5. This is because the atmosphere was fairly dry after the passage of the cold front. Considering these small PWV values, the general tendency of the GPS results agreed well with those obtained with the radiometer except after $18 \mathrm{UT}$.

We again refer to the radiosonde result at $23 \mathrm{UT}$, which agrees better with the results from GPS than radiometer. Therefore, we suspect that the radome of the radiometer was wet with dew after 18 UT. We further calculated a bias and RMS value, except for the period of morning dew, and obtained $-0.44 \mathrm{~mm}$ and $1.79 \mathrm{~mm}$, respectively. Because a radiometer can provide PWV every a few minutes when the view angle is fixed to the zenith, we should repeat a similar comparison with a better time resolution.

\subsection{Consistency of PWV values determined with closely located GPS receivers}

In order to confirm that these GPS results represent variations in water vapor, we investigated the consistency among the GPS results. We will discuss the comparison of detailed PWV variations detected with three GPS receivers that were closely located, i.e. within several hundred meters. We here refer to the results collected at CENT, PRIM and JUNI (see Table 1) during the Yamagawa campaign.

For normal GPS measurement the lowest elevation angle of a satellite is set as $15^{\circ}-20^{\circ}$. Then, if we assume that a major part of the water vapor is distributed below about $3 \mathrm{~km}$, the GPS-derived PWV corresponds to an average over a horizontal distance of about $20 \mathrm{~km}$. So, the GPS results should not show significant differences between the three sites.

We present in Fig. 7 the PWV at the three sites taken on June 16 with a time resolution of $6 \mathrm{~min}$. Note that these three PWV were estimated for each baseline. The reference point was TSKB. PWV changes from 30 to $60 \mathrm{~mm}$ were affected by the evolution of a Baiu front. Detailed time variations of PWV were very consistent between the three sites, except that the results at JUNI started to depart from the other two traces after $19 \mathrm{UT}$, showing a maximum deviation of $8 \mathrm{~mm}$. This could have been caused by an "end effect", a loss of data at the end of a day, which sometimes occurs near the end of a session. During 0 and 18 UT, as shown in Fig. 7, the discrepancies in PWV among the three sites can be estimated at 2 to $4 \mathrm{~mm}$. This seems to be caused by both coordinate error and multipath effects, the difference in radio wave receiving environments, because these discrepancies exist systematically over the entire day. Therefore, these values seem to indicate the limit of the absolute accuracy on $6 \mathrm{~min}$. determination with GPS.

\subsection{Ceilometer}

We compared the GPS results estimated with a division number of 240 for the tropospheric parameter using 4-hour period GPS data (time resolution of $1 \mathrm{~min}$.) and ceilometer data.

We obtained ceilometer data every $12 \mathrm{sec}$. during the Yamagawa campaign, which provided the bottom heights of the lowest two cloud layers. By assuming that the rela- 


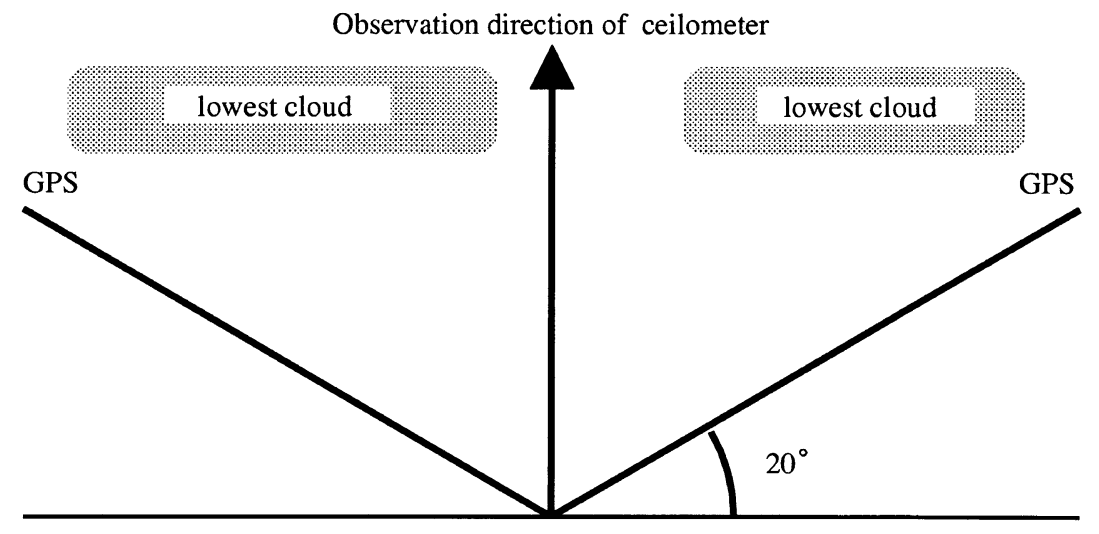

Observation site of both ceilometer and GPS

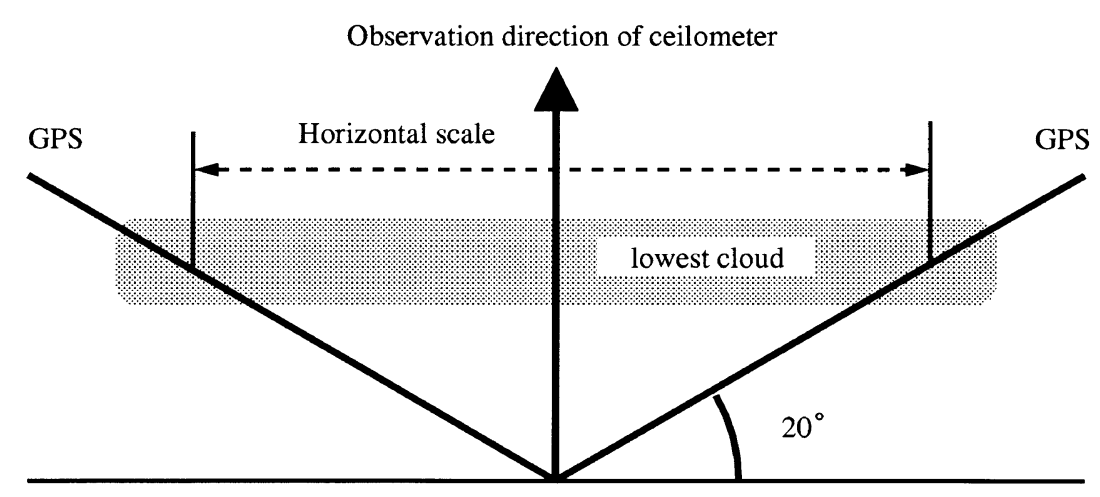

Observation site of both ceilometer and GPS

Fig. 8. Schematic cross sections of view angles of a GPS receiver. Top and bottom panels, cases with a low and high cloud-bottom, respectively.

tive humidity is $100 \%$ and that the temperature lapse rate is $0.65 \mathrm{~K} / \mathrm{km}$ in a cloud, PWV in these cloud layers can be inferred. It is noteworthy that PWV derived with a ceilometer corresponds to about 5 to $10 \%$ of the total PWV in a column. We employed the ceilometer data as a reference for short term variation of PWV, although the accuracy of the inferred PWV value may not be so good.

When high-time resolution records are compared between GPS and a ceilometer, we must be careful as to whether the same volume of the atmosphere is being observed. GPS determines PWV averaged by all GPS satellites in a cone with a minimum elevation angle of $20^{\circ}$, as schematically shown in Fig. 8. Note that ray paths may not be distributed homogeneously in the cone in Fig. 8, because more GPS satellites appear in the southern sky over the site located in the middle latitude, especially at low elevation angle. Moreover, GPS satellites move faster in the north-south direction. Therefore, the population density of ray paths is not uniform in the conic volume in Fig. 8. On the other hand, a ceilometer provides PWV information just above the site. Further, the time variations may not correlate well when scattered clouds are distributed at high altitudes.

We selected 8-12 UT when the cloud bottom height was as low as $100 \mathrm{~m}$, therefore, we could expect a better agreement, as suggested in Fig. 8. In such a case, the PWV value in the low clouds should be large because both the atmospheric density and saturation temperature are high.

Figure 9 presents the bottom height of the lowest cloud at Yamagawa on June 17, 1996. When a thick cloud existed at a low altitude, the laser pulse from the ceilometer was unable to penetrate into the cloud. On the other hand, with a thin cloud the laser pulse could reach higher altitudes, and detected weak scatterers distributed over a wide height range. Thus, the long vertical lines in Fig. 9 indicate less cloud activity.

Figure 10 shows detailed variations of the bottom and top heights of the lowest cloud during 8 and 12 UT on June 17. The cloud bottom varied from 100 to $150 \mathrm{~m}$. We estimated PWV contained in the lowest cloud by referring to the surface temperature at the Kagoshima weather station. Note that we also applied a moist adiabatic lapse rate to a temperature profile below the lowest cloud because radiosonde one launching at 0 UT on June 17, provided a temperature lapse rate more close to a moist adiabatic lapse rate than a dry one.

In order to compare small scale perturbations of PWV, we applied a high frequency pass filter with a cut-off period of 15 min., and plotted the results in Fig. 11 (doted line) for a ceilometer. Note that we further applied the running mean over 9 points.

Because we only wished to extract the systematic (not 


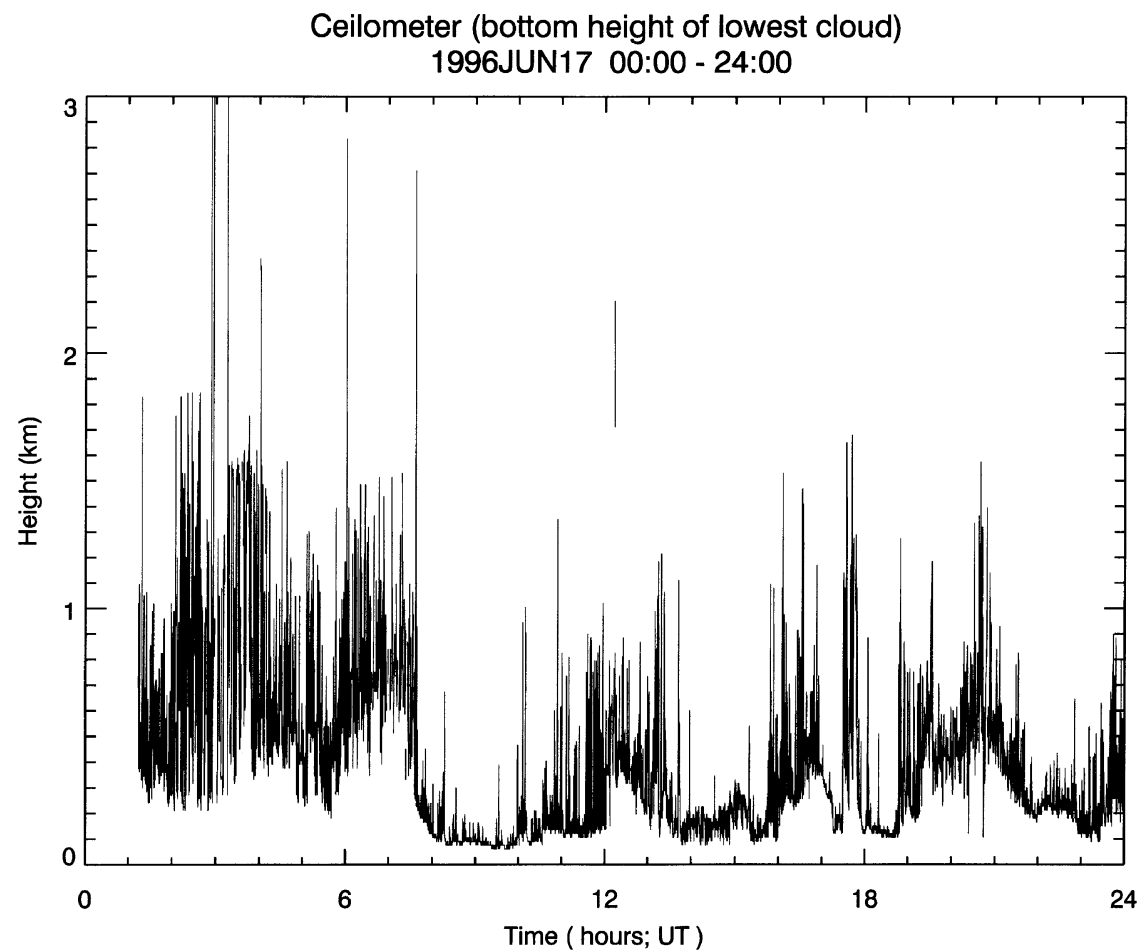

Fig. 9. Bottom height of the lowest cloud detected with a ceilometer at Yamagawa on June 17, 1996. These results were obtained with a time resolution of $12 \mathrm{sec}$.

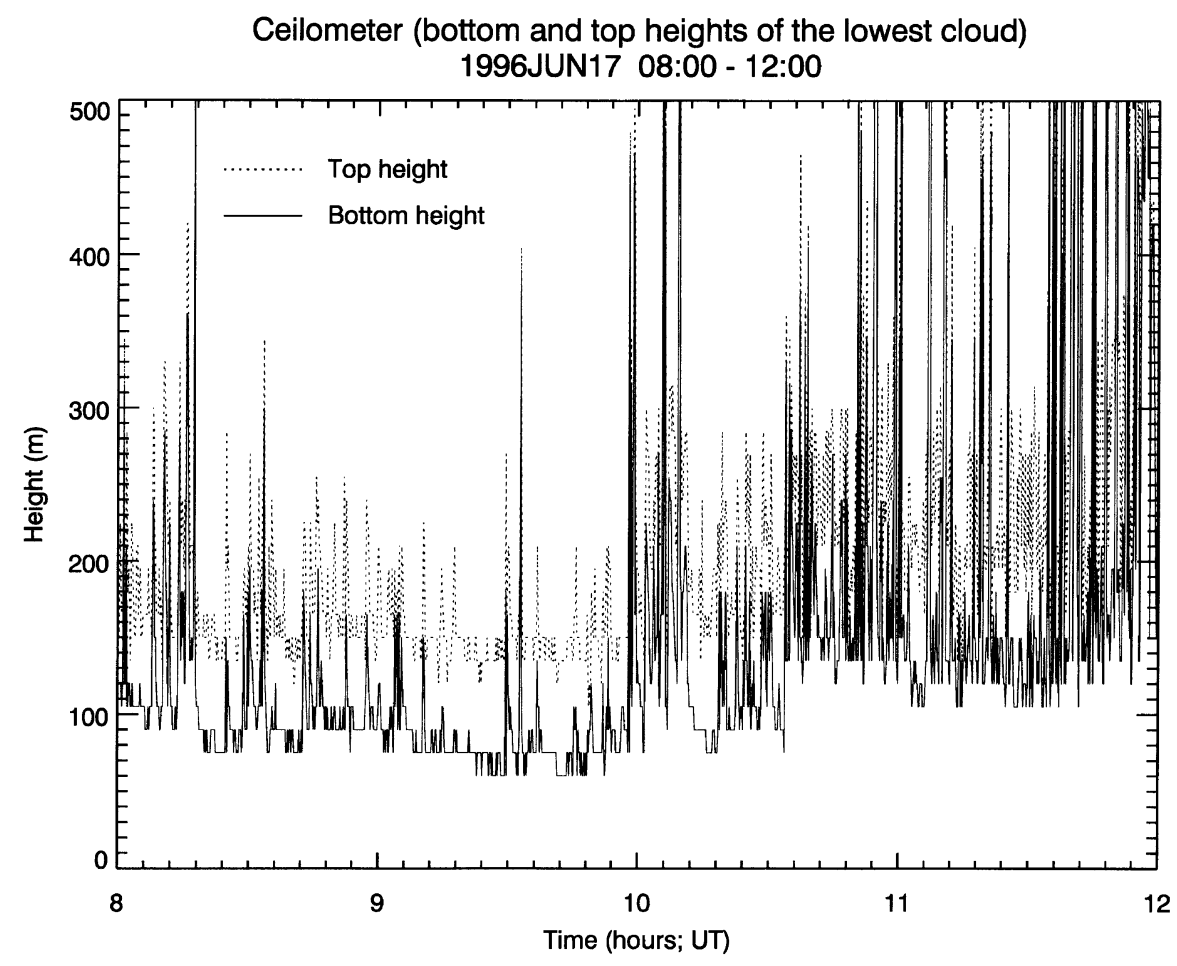

Fig. 10. Bottom (solid line) and top (dotted line) heights of the lowest cloud determined with a ceilometer at Yamagawa during 8 and 12 UT on June 17, 1996.

random) changes from the ceilometer data and to compare them with the GPS results, we again applied a band-pass filter with cut-offs of 6 and $15 \mathrm{~min}$. for the original ceilometer data, and further decreased the number of data points by averaging every 5 points. The results are also shown in Fig. 11 (solid line). Note that these results are displayed with a unit of delay in $\mathrm{m}$ (not PWV).

For GPS, we also applied a high frequency pass filter with a cut-off period of $15 \mathrm{~min}$. The results for both the ceilometer and GPS are shown in the top panel of Fig. 12. The general 


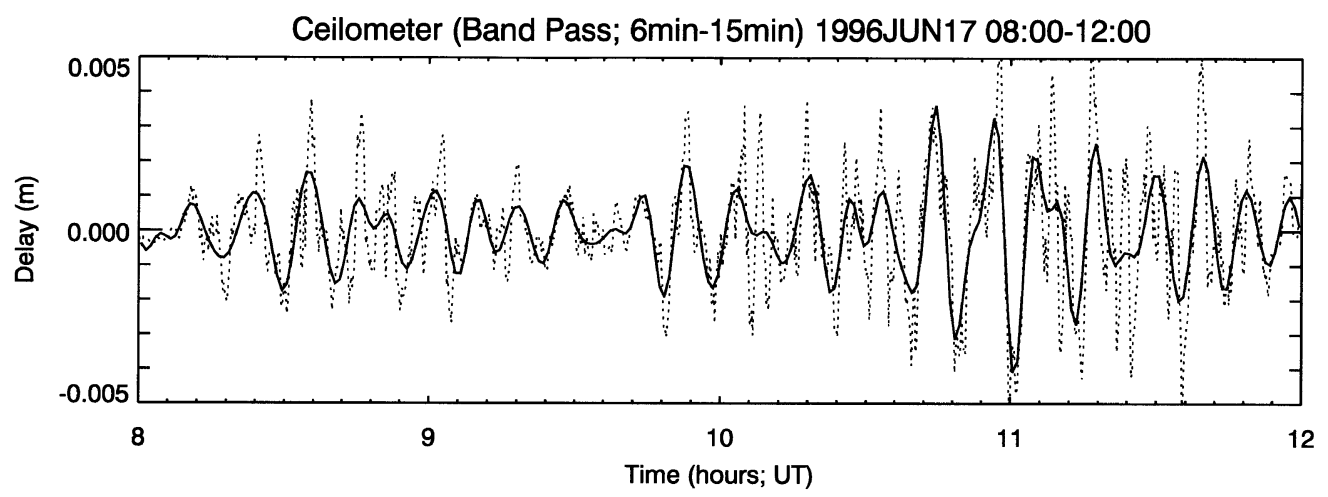

Fig. 11. Wet zenith delay inferred from ceilometer measurements during 8 and 12 UT on June 17, 1996. Note that the doted line shows short term variations after processing with a high-pass filter with a cut-off at $15 \mathrm{~min}$. The solid line shows the same except for a band-pass filter for $6-15$ min. components.
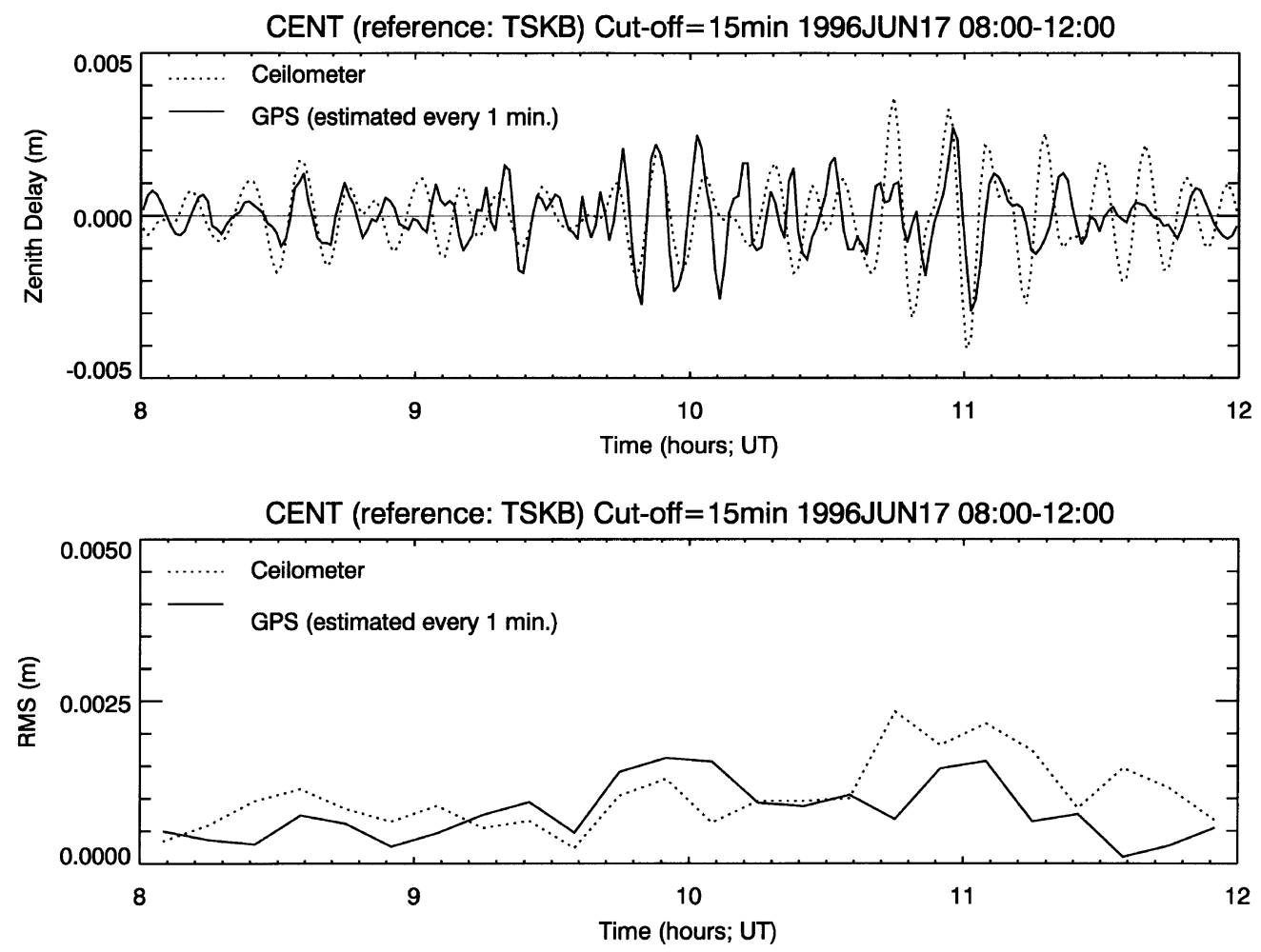

Fig. 12. Comparison between the wet delay estimated with a ceilometer (see solid line of Fig. 11) and GPS ZD at CENT analyzed every one min. during 8 and 12 UT on June 17, 1996. The top panel shows zenith delay variations and the bottom panel shows the associated RMS, respectively. The band-passed results obtained with a ceilometer are plotted as a dotted line. Note that these variations are expressed in unit of length.

characteristics of the PWV variations between GPS and the ceilometer are in good agreement. In particular, the variations were almost in-phase in the three periods of around 8:30, 9:30-10:00 and 11:00 UT. During the first two periods the cloud bottom height was below $100 \mathrm{~m}$, as shown in Fig. 10.

In order to compare their amplitudes, we also plotted the variances for both the ceilometer and GPS in the bottom panel of Fig. 12. These variances were calculated as the root mean square (RMS) of every 10 points. Generally, the RMS values of both results are in agreement in a range up to $1.5 \mathrm{~mm}$ in the unit of propagation delay. In particular, these RMS values agreed better between GPS and the ceilometer in the period in which the cloud bottom height was about
$100 \mathrm{~m}$, i.e. at 8:00-10:30 UT. In this period, both results were in agreement up to about $1.0 \mathrm{~mm}$.

Although we may not have accurately obtained the total PWV contained in the lowest cloud from the ceilometer measurements because of some assumptions (the temperature lapse rate of $0.65 \mathrm{~K} / \mathrm{km}$ and the relative humidity of $100 \%$ in clouds), the perturbation part of the PWV could be delineated from the former analysis. We would not expect exact agreement of the fluctuating component of PWV between the ceilometer and GPS measurements. However, a good correlation between the ceilometer and GPS results in Fig. 12 suggests that the latter could show the short period PWV variations in the lower atmosphere. Moreover, these results suggest that GPS has the potential for more detailed 

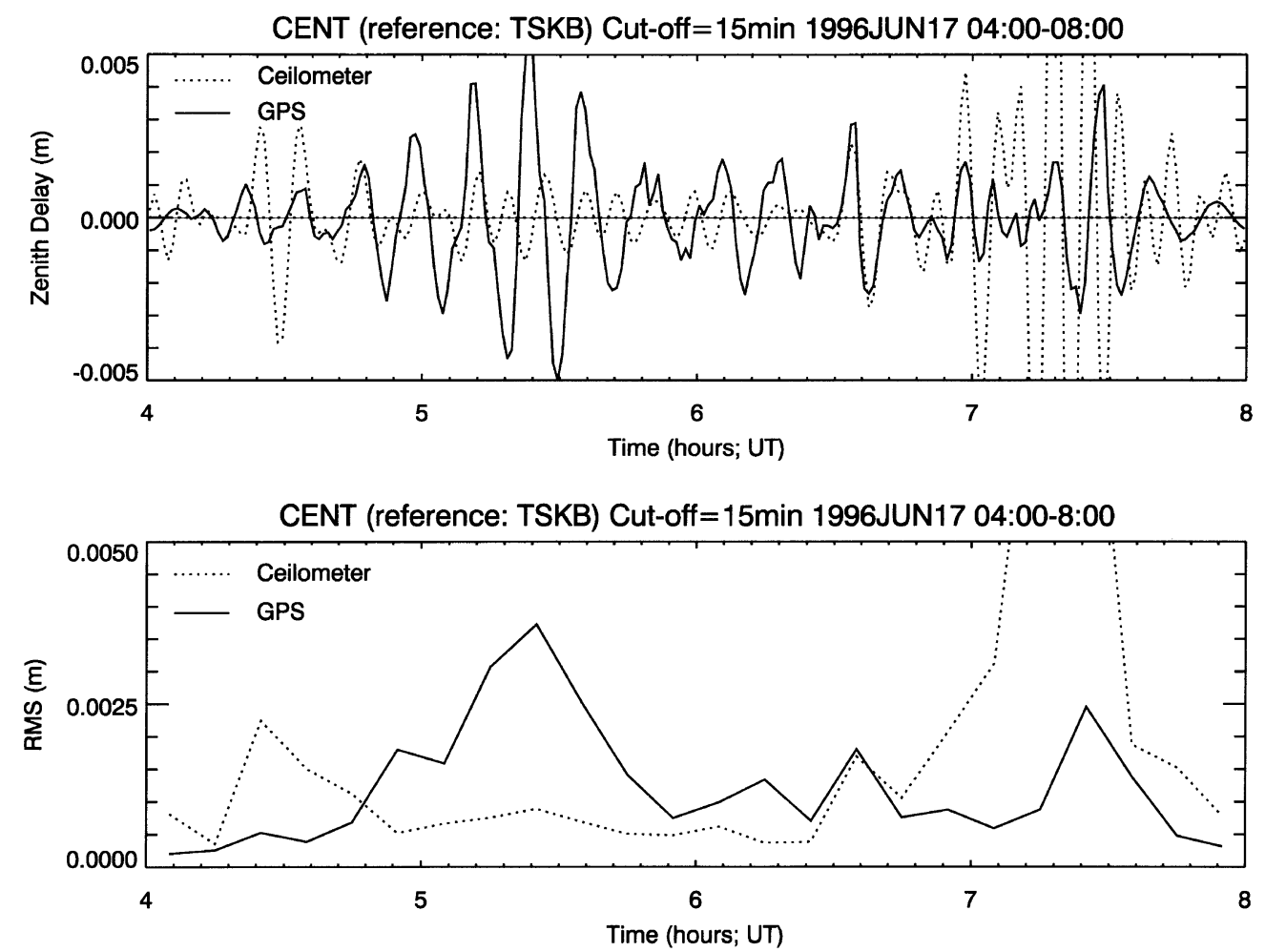

Fig. 13. The same as Fig. 12 except that it is for 4 to 8 UT on June 17, 1996 (i.e. the period 4 hours before Fig. 12).
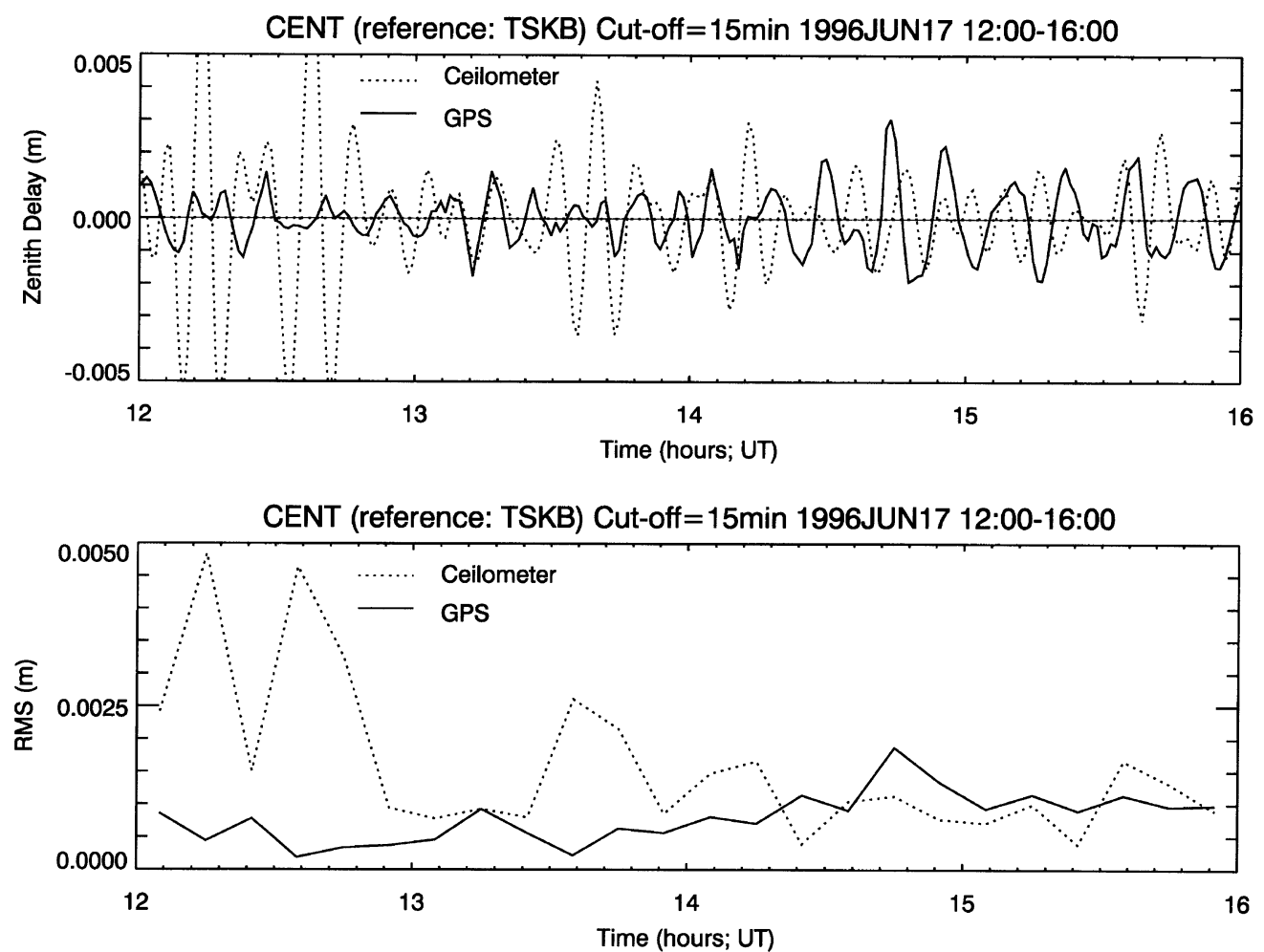

Fig. 14. The same as Fig. 12 except that it is for 12 to 16 UT on June 17, 1996 (i.e. the period 4 hours after Fig. 12).

study of water vapor variation by combining with a tool such as ceilometer and GPS satellite positions in the sky (i.e. slant wet delay) than by the ordinary PWV variation alone.

We also refer to the GPS and ceilometer results derived us- ing the same process in the period before and after 4 hours (i.e. 4-8 UT and 12-16 UT), and present them in Figs. 13 and 14, respectively. Figure 13 shows PWV variations during 4 and 8 UT on June 17, when the bottom height of the lowest cloud 
Table 5. The results of comparison of ceilometer and GPS (CENT) results by cross correlation processing during 8:30 and 11:30. These results were processed by dividing 4 hour PWV variations into $30 \mathrm{~min}$. intervals. Time lags were described on the basis of ceilometer PWV variations. Also, the RMS values of both measurements are given for each section.

\begin{tabular}{ccccccc}
\hline & \multicolumn{2}{c}{ Cross correlation } & & \multicolumn{2}{c}{ RMS (mm) } \\
\cline { 2 - 3 } \cline { 6 - 7 } & Lag (min) & Correlation & & Ceilometer & GPS \\
\hline 8:30-9:00 & 0 & 0.724 & & 0.896 & 0.610 \\
9:00-9:30 & -3 & 0.140 & & 0.707 & 0.776 \\
9:30-10:00 & 0 & 0.794 & & 0.968 & 1.29 \\
$10: 00-10: 30$ & -2 & 0.084 & & 0.861 & 1.19 \\
$10: 30-11: 00$ & 0 & 0.484 & & 1.80 & 1.13 \\
$11: 00-11: 30$ & -2 & 0.659 & & 1.66 & 1.09 \\
\hline
\end{tabular}

varied from about $400 \mathrm{~m}$ to $1500 \mathrm{~m}$, as shown in Fig. 9. In this case, we suspect that cloud top and bottom heights from the ceilometer results did not represented "identical" cloud layers but "disconnected" ones, and that the contribution of the lowest cloud for PWV variations decreases for two reasons: a difference in observational areas and a reduction of saturated vapor quantity at a high bottom height. Therefore, both the GPS and ceilometer results greatly disagreed in their amplitudes, phases and variances except at around 6:30 UT. Also, Figure 14 shows PWV variations during 12 and 16 UT. In the first half of this period, the bottom height of the lowest cloud varied from about $200 \mathrm{~m}$ to $1000 \mathrm{~m}$. On the other hand, the bottom height varied around $200 \mathrm{~m}$ in the latter half, as shown in Fig. 9. The GPS and ceilometer results reflected these conditions, as shown in Fig. 14. That is, although the phases of PWV variations generally disagreed, their amplitudes (i.e. variances) agreed well within about $1 \mathrm{~mm}$ in the latter half of this period.

Again, we carried out cross correlation analysis for the above-mentioned period during which the GPS and ceilometer results agreed well, that is, during 8 and 12 UT on June 17. Table 5 shows the cross correlation coefficients of the GPS results as to the ceilometer ones. We divided 4 hour PWV variations into $30 \mathrm{~min}$. intervals, except for both ends of the window. Also, Table 5 presents the RMS value of each result in the respective periods. As shown in this table, cross correlation coefficients exhibited larger values with a level of about $0.65-0.80$ in the above-mentioned three periods, i.e. at around 8:30, 9:30-10:00 and around 11:00 UT.

\section{Summary}

We discussed in this paper the estimation of PWV by means of high time resolution GPS measurements, and aimed to apply the results for observation of meso-scale meteorological phenomena. We used GPS records collected during two GPS campaigns in Yamagawa and Shigaraki. We now summarize the main conclusions of this study.

1) We investigated a set of analysis parameters of BERNESE suitable for this study. First, we examined time variations of $Z D$, changing time resolution of the analysis, and found that detailed time variations of ZD obtained with better time resolutions had similar structures. The mean value of ZD averaged over 24 hours was nearly the same regardless of the division number. An average of the 24-hour mean ZD among the 7 cases was $0.037 \mathrm{~m}$ with a standard deviation of $0.0017 \mathrm{~m}$.

2) From a comparison of the GPS and radiosonde results, we found that PWV variation of 6 min. GPS determination can be correctly estimated with a discrepancy of as little as $3.10 \mathrm{~mm}$ in RMS except for a bias of $8.25 \mathrm{~mm}$ from a coordinate error and an interaction with the coordinate determination.

3) The 6 min. GPS PWV agreed well with the radiometer measurement with a mean difference within an accuracy of $1.43 \mathrm{~mm}$ and in the detailed variation within a RMS value of $2.44 \mathrm{~mm}$ except for the period of precipitation and morning dew.

4) From comparison of detailed PWV variations detected with three GPS receivers that were closely located, i.e. within several hundred meters, we found that the discrepancy of PWV among the three sites is estimated as 2 to $4 \mathrm{~mm}$, except for the "end effect" which earned a larger discrepancy.

5) When the cloud bottom height was as low as $100 \mathrm{~m}$, and the horizontal structure of the cloud layer was fairly homogeneous, the PWV variations calculated from the ceilometer data agreed very well with the GPS-PWV variation within a RMS value of $1.0 \mathrm{~mm}$ in propagation delay, showing periodic perturbations with a time scale of 6-15 min. On the basis of these comparisons, we obtained a primary confirmation of PWV perturbation accuracy estimated from GPS data with a time resolution of $1 \mathrm{~min}$.

From these results, we concluded that PWV estimations with high time resolution from GPS data are possible. As a meteorological measurement tool, GPS has the potential to detect small changes in water vapor content.

Acknowledgments. We wish to express our hearty gratitude to Professor T. Tanaka of the Disaster Prevention Research Institute (DPRI), Kyoto University, for the progressive discussion and helpful advice, and for providing GPS data, software and instruments for this study. We are very grateful to Dr. T. Nakano of the DPRI, Kyoto University, for his instructive advice, kind encouragement and kindhearted help, especially regarding the BERNESE software. We also greatly thank Dr. R. Otani of the Geological Survey of Japan, for his constructive advice, useful suggestions and comments. We show appreciation to Professor I. Naito of the National Astronomical Observatory and Dr. F. Kimata of the Graduate School of Science, Nagoya University, for their kind advice and encouragement in this study. We also thank Drs. T. Kato and S. Nakao of the Earthquake Research Institute, University of Tokyo, for their BERNESE training course and helpful advice. We wish to thank Dr. S. Miyazaki of the Geographical Survey Institute for his kind advice and encouragement, and for providing the GSI data. Thanks are also due to all staff and operators who took part in the Yamagawa Campaign. We are also thankful to all staff and operators who took part in Shigaraki campaign. This study is supported by the Japanese GPSMeteorology project of Science and Technology Agency (STA), Japan. The author was supported by a grant of the Japan Society for the Promotion of Science (JSPS) under the Fellowships for Japanese Junior Scientists. 


\section{References}

Askne, J. and H. Nordius, Estimation of tropospheric delay for microwaves from surface weather data, Radio Sci., 22, 379-386, 1987.

Bevis, M., S. Businger, T. A. Herring, C. Rocken, R. A. Anthes, and R. H. Ware, GPS meteorology: Remote sensing of atmospheric water vapor using the Global Positioning System, J. Geophys. Res., 97, 15,787-15,801, 1992.

Businger, S., S. R. Chiswell, M. Bevis, J. Duan, R. Anthes, C. Rocken, T. M. Exner, T. VanHove, and F. Solheim, The promise of GPS in atmospheric monitoring., Bull. Amer. Meteor. Soc., 77, 5-18, 1996.

Davis, J. L., T. A. Herring, I. I. Shapiro, A. E. E. Rogers, and G. Elgered, Geodesy by radio interferometry: Effects of atmospheric modeling errors on estimates of baseline length, Radio Sci., 20, 1593-1607, 1985.

Elgered, G., J. L. Davis, T. A. Herring, and I. I. Shapiro, Geodesy by radio interferometry: Water vapor radiometry for estimation of the wet delay, J. Geophys. Res., 96, 6541-6555, 1990.
Hopfield, H. S., Two-quartic tropospheric refractivity profile for correcting satellite data, J. Geophys. Res., 74, 4487-4499, 1969.

Iwabuchi, T., I. Naito, S. Miyazaki, and N. Mannoji, Precipitable water vapor moved along a front observed by the Nationwide GPS Network of Geographical Survey Institute, TENKI, 44, 767-784, 1997.

Kuo, Y.-H., Y.-R. Guo, and E. R. Westwater, Assimilation of precipitable water into a mesoscale numerical model, Mon. Wea. Rev., 121, 12151238,1993

Rocken, C., R. Ware, T. VanHove, F. Solheim, C. Alber, and J. Johnson, Sensing atmospheric water vapor with the Global Positioning System, Geophys. Res. Lett., 20, 2631-2634, 1993.

T. Yoshihara (e-mail: yoshihara@kurasc.kyoto-u.ac.jp), T. Tsuda, and K. Hirahara 